\title{
Militância, repressão e silêncio: relato de uma experiência com a memória operária
}

\author{
Marco Aurelio Santana*
}

INTRODUÇÃO

A RELAÇÃo ESTABELECIDA ENTRE PESQUiSAdor e pesquisado é um dos pontos mais ricos na experiência com a história oral. Esta relação, em um contexto de geração de documentos, tem dado sua importante colaboração ao relativizar posturas mais rígidas sobre a separação entre sujeito e objeto no campo da pesquisa. Grande parcela da força deste procedimento vem do fato de que o uso do testemunho oral possibilita ao pesquisador o acesso a perspectivas e nuances que podem estar fora do seu alcance a partir de outras fontes documentais.

O diálogo entre entrevistador e entrevistado, contudo, nem sempre se dá de forma facilitada. Além das dificuldades - em muitos casos, já inerentes ao processo de entrevista -, podem-se, dependendo do estudo, enfrentar problemas ainda mais sérios. Exemplo claro é o trabalho de entrevista com indivíduos que passaram por experiências-limite, marcadas por violência física e/ou psicológica, e que têm no campo aberto da entrevista a chance de falar e/ou calar sobre os intensos traumas que sofreram. Isto traz ao pesquisador, entre outras questões, o lidar não só com as resistências conscientes e inconscientes do entrevistado, mas também com a forte emoção que pode aflorar ao longo do processo.

Nosso objetivo é analisar as dificuldades encontradas na realização de entrevistas junto a um grupo de militantes operários do Rio de Janeiro. Eles enfrentaram as agruras de viver a perseguição da ditadura militar instalada no Brasil em 1964.

* Professor Adjunto de Sociologia da Universidade do Rio de Janeiro (UNIRIO). O autor gostaria de agradecer aos pareceristas da revista História Oral pelas sugestões que fizeram ao texto. 
A análise empreendida pode contribuir para lançar luz sobre alguns dos mecanismos pelos quais determinado grupo submetido a práticas repressivas efetua seu trabalho de memória.

\section{O GRUPO: APROXIMAÇÃO E RESISTENNCIA}

A idéia de contato com o grupo estudado surgiu a partir de um projeto de pesquisa acerca dos trabalhadores metalúrgicos do Rio de Janeiro e de suas lutas no pré-64. ${ }^{1}$

Sabíamos, a partir da literatura pertinente, que a categoria obtivera papel de destaque no movimento sindical daquele período. ${ }^{2}$ Nestes estudos, são várias as referências sobre a participação dos metalúrgicos em momentos marcantes da trajetória dos trabalhadores brasileiros naquela conjuntura. ${ }^{3}$ Segundo as indicações, os metalúrgicos tiveram uma presença de peso em congressos e reuniões sindicais. Nomes identificados à categoria ocuparam cargos na direção de importantes órgãos intersindicais que orientavam e coordenavam a luta sindical. ${ }^{4}$ Além desta participação na esfera organizativa, os metalúrgicos marcaram presença na esfera reivindicativa, colaborando com as greves ocorridas no período.

Grande parte do trabalho que resultou neste aumento da inserção da categoria no cenário político mais amplo deveu-se à militância comunista. A ação dos comunistas junto a esta categoria, que já se dava historicamente desde os primórdios de seu órgão associativo, teve nos anos 50 seu 'período de ouro'. Em nível nacional, apesar de clandestino, o Partido Comunista Brasileiro (PCB), em aliança com o setor progressista do Partido Trabalhista Brasileiro (PTB), conseguiu conquistar postos importantes na estrutura sindical oficial, buscando utilizá-los para orientar o movimento dos trabalhadores brasileiros.

No caso dos metalúrgicos do Rio, foi por meio do intenso trabalho no interior das empresas, via conselhos sindicais de fábrica, que os comunistas não só reforçaram seu poderio no interior do sindicato - chegando a ser a força política mais relevante na diretoria da entidade -, como também garantiram aos metalúrgicos importantes espaços de participação e ação na luta por seus direitos. ${ }^{5}$

O governo militar foi bastante duro com os metalúrgicos - na medida da importância obtida por sua entidade -, assim como com um grande número de sindicatos. Os metalúrgicos tiveram sua sede invadida por tropas policiais e seus arquivos destruídos. Toda uma geração de militantes foi submetida a perseguições, prisões, delações, inquéritos e banimento. É a história deste grupo e de sua categoria que procuraremos reconstituir.

A pesquisa partiu de um exaustivo trabalho de análise em fontes escritas. Jornais e revistas, bem como documentos produzidos no âmbito sindical, serviram de lastro inicial ao nosso trabalho. Desde o começo, estava claro que, para trabalhar 
com uma parcela da memória operária do período - de difícil acesso pela documentação escrita - utilizaríamos o testemunho oral. A proposta era realizar entrevistas com lideranças operárias e trabalhadores que, direta ou indiretamente, participaram da construção dessa história. Esta perspectiva foi ainda mais reforçada, abrindo nova importância para as fontes orais, quando se tornou evidente, que os arquivos sindicais, por uma série de fatores, ${ }^{6}$ seriam bastante limitados aos nossos interesses. A história oral cumpriria papel importante no esclarecimento de pontos e lacunas nas fontes escritas, e na percepção das representações dos atores sociais sobre a própria história.

Como, no decorrer da pesquisa com as fontes escritas, travamos contatos com a direção sindical para a consulta dos acervos da entidade, solicitamos a eles indicações de possíveis entrevistados. Fomos informados da existência de um órgão de aposentados do sindicato e de sua rotina de reuniões. Nesse sentido, o Grêmio dos Veteranos do Sindicato dos Metalúrgicos do Rio de Janeiro foi escolhido como o primeiro ponto de contato, já que congregava uma boa parte dos militantes de diversos períodos e das diversas tendências políticas que atuaram na vida da entidade sindical.

Eleito o locus privilegiado para o desenrolar da pesquisa, era necessário que se fizessem contatos para o início das entrevistas. Conseguimos agendar uma primeira ida ao Grêmio, que serviria para a apresentação da pesquisa e de suas intenções de trabalho.

Esperada por nós com grande ansiedade, a primeira visita foi um fiasco. A estratégia utilizada inicialmente partiu da idéia de que o contato deveria ser feito de forma coletiva, diretamente com o grupo. Esta escolha deveu-se ao fato de não conhecermos ninguém que pudesse atuar, individualizadamente, como 'ponte' até os outros militantes. Além disso, achávamos que, pelo Grêmio, conseguiríamos uma certa legitimação institucional que, acreditávamos, abriria novas possibilidades e facilitaria contatos futuros. Estávamos certos de que este tipo de aproximação seria o melhor, ainda mais que indicamos, no agendamento, o fato de já termos mantido contatos com a diretoria do sindicato. Contudo, tal perspectiva logo configurou-se um terrível engano.

No primeiro contato, os 'velhos' do Grêmio nos receberam com muita agressividade. Quase sem nos dar direito à palavra, ${ }^{7}$ ora nos identificavam com a então recém-eleita diretoria do sindicato, ligada à Central Única dos Trabalhadores (CUT), de quem divergiam seriamente, ora insinuavam que éramos agentes da polícia e que poderíamos usar as informações contra eles. Além disso, destilaram seu rancor em relação a outros pesquisadores que, no passado, lhes procuraram e desapareceram com os seus documentos, guardados por eles já de longa data. Surpreendidos, fomos colocados em uma situação bastante delicada. 
Para que se tenha uma idéia do teor das questões que nos eram colocadas, vale indicar a postura de um dos integrantes do Grêmio - que insistia em perguntar-nos, em voz alta, mesmo após já o termos dito, o que fazíamos e de onde éramos. Ao lhe responder que éramos pesquisadores da universidade, o que, para nós, além ser nossa óbvia e verdadeira condição, serviria para tranqüilizá-los, ele retrucou: "mas quem me garante que, depois de estudante, você não vai entrar para a Polícia Federal e usar as informações da pesquisa?".

No momento mais duro da 'sabatina', diante das pressões e do acuamento, pensávamos: o que temiam estes senhores de idade avançada, vivendo em um regime de franca democracia e se reunindo em uma sala perdida no subúrbio carioca? E mais: por que representávamos nossa atividade em um linguajar tão afeito ao inquérito policial - queríamos informantes, fazer algumas perguntas, colher depoimentos, pistas etc.?8

A partir daquele momento, os temores dos entrevistados passariam a estar em posição de destaque em nossas preocupações. O impacto inicial serviu como elemento para reavaliarmos alguns pontos em nossa atuação. Tendo em vista os argumentos contrários à pesquisa, colocados pelo grupo, pôde-se perceber que o processo de aproximação não levou em consideração a possibilidade do surgimento do grau de problemas que enfrentamos. Além disso, avaliou-se, sem muitos elementos, que a indicação de conhecimentos e relações com a diretoria do sindicato garantiria uma certa legitimidade ao trabalho frente ao grupo.

Nossa estratégia de contato precisou ser reavaliada. Passamos a contatar os membros do Grêmio de maneira individual. Ao longo do tempo, esta modalidade se mostrou muito mais eficiente. Voltamos a abordar aqueles trabalhadores que, mesmo de forma tímida, haviam demonstrado algum interesse por nosso projeto ou, pelo menos, menos rejeição a ele.

Recomeçamos pelos que haviam sido menos agressivos quando do contato coletivo. Então, alguns deles, mesmo que hesitantes, acabaram se prontificando a falar.

Sentíamos, claramente, os efeitos da alteração da estratégia de aproximação. Fomos conseguindo, a cada entrevista, a indicação de outro possível entrevistado. ${ }^{9}$ Utilizávamos, a cada novo contato, o fato de já termos conversado com outros integrantes do Grêmio, informando-lhe que eles o haviam indicado. Em alguns casos, os já entrevistados se prontificavam em fazer o contato prévio com o integrante que indicara.

Com o passar do tempo, voltamos ao Grêmio e já tínhamos contato com um bom número de trabalhadores. A sensação de estranhamento do grupo ia diminuindo, à medida que fazíamos questão de demonstrar que conhecíamos alguns deles. O espectro de entrevistados ultrapassou até mesmo os limites do Grêmio. Isto foi 
importante para a pesquisa, já que alguns aposentados não freqüentavam a entidade, embora mantivessem contato com os colegas.

A ampliação do número de entrevistados garantiu maior inserção no grupo, alterando, em certa medida, a forma como nos viam. Porém, ainda não foi de todo suficiente para mudar a visão dos mais resistentes. Mais tarde saberíamos o porquê.

\section{NEGOCIANDO COM AS RESISTÊNCIAS}

Mesmo com todos os avanços nas entrevistas, sentíamos que ainda poderíamos conseguir mais com nossos informantes. Isto era dificultado pelos problemas gerados por nossa primeira ida ao Grêmio. O medo causado pela identificação do nosso trabalho com as atividades policiais, que tanto tinham feito sofrer aquele grupo, e que era mencionado recorrentemente, limitava bastante as nossas entrevistas. Nós nos sentíamos intimidados e temerosos dos possíveis passos em falso. Os próprios entrevistados também se restringiam quando certas questões eram enfocadas. $\mathrm{O}$ diálogo entre entrevistador e entrevistado transformou-se em um verdadeiro jogo de esconde-esconde, tornando-se difícil conseguir informações.

Quase nada se falava, por exemplo, quando se tratava da participação de militantes comunistas nas fileiras do sindicato no pré-64. Sabíamos, já até mesmo pela via do cruzamento de informações, que muitos dos entrevistados haviam sido militantes do PCB naquela época. Poucos, porém, o confirmavam, durante as entrevistas. ${ }^{10}$ Entendíamos isto e procurávamos conseguir informações dentro dos limites de cada entrevistado. Aceitávamos as limitações se não somente em um certo respeito ao entrevistado em seu direito de calar sobre os pontos que desejasse, mas também devido ao fato de que a insistência pura e simples poderia nos levar à ruptura do contato e problemas maiores no futuro.

A dificuldade de obter informações sobre a atuação comunista aumentou meu interesse, iniciando o processo de definição de um outro objeto de pesquisa que se distinguia e especificava do tema geral trabalhado em equipe. Quanto mais os entrevistados silenciavam sobre os comunistas, mais interessado neles eu me tornava. A história oral ia auxiliando na delimitação de meu objeto de pesquisa. ${ }^{11}$

Visando obter mais informações sobre questões e eventos dos quais os entrevistados se esquivavam nas entrevistas, tornou-se necessária uma outra redefinição de estratégia. Ao longo do processo de entrevistas, ficou sempre muito claro que, se fôssemos direto à questão relativa à história do sindicato ou da atuação do entrevistado como militante político, aumentaríamos a resistência ao trabalho. Diante das resistências encontradas, reforçamos o emprego de entrevistas lastreadas na história de vida. ${ }^{12}$ Elas serviram, apropriadamente, para 'quebrar' algumas resistências 
iniciais. Pedíamos aos entrevistados que falassem sobre a origem familiar, infância etc. Depois, aos poucos, íamos ligando a sua história à história do sindicato, aumentando o detalhamento sobre as questões da pesquisa. Isso facilitou o relacionamento com o entrevistado e, em conseqüência, a obtenção de informações para o estudo. A partir de então, conseguimos dados tanto sobre a vida do entrevistado - que ampliavam nossa percepção [sobre] os fatos -, como sobre sua atuação no sindicato.

\section{AS PARTICULARIDADES DO COLETIVO: UM SILÊNCIO, MUITAS FACES}

Apesar da alteração de estratégia e de toda a cautela utilizada, permanecia o problema do silêncio no tocante a alguns assuntos. Achávamos que aquelas lacunas eram fruto, simplesmente, de uma desconfiança que eles nutriam em relação à pesquisa. Tal desconfiança era o único elemento generalizador do silêncio de pessoas às vezes muito diferentes.

Ficava patente que, por terem sido submetidos à práticas repressivas (como perseguições políticas, julgamentos, prisões, delações etc.), alguns integrantes guardavam ainda vivas as lembranças de todo aquele duro processo.

Porém, atribuir somente à desconfiança coletiva de que a pesquisa mantinha ou manteria relações com a polícia e o decorrente receio dos entrevistados de serem vitimados, outra vez, pela repressão, parecia não dar conta de toda a complexidade do problema. Partindo deste tipo de constatação, pôde-se, aos poucos, perceber que o silêncio de nossos entrevistados não se devia apenas a um fator, mas a vários. Cada silêncio, ainda que enfeixado em uma roupagem coletiva, silenciava o seu motivo.

De forma geral, os entrevistados, ao trabalharem a memória no processo das entrevistas, encontraram assuntos delicados sobre os quais desejavam calar. ${ }^{13}$ Silêncio que, sob uma forma una, escondia uma multiplicidade de motivos. Por terem enfrentado situações-limite, nas quais os inquéritos, interrogatórios e depoimentos ocuparam papel de destaque, nossos entrevistados, ao serem por nós argüidos, lembravam-se, sempre, de circunstâncias que os incomodaram no passado.

A própria situação da entrevista já era sentida, em muito casos, como um momento tenso, em que, a qualquer momento, poderíamos ouvir, como ocorreu diversas vezes: "Esta pergunta já me foi feita durante as investigações policiais". Em alguns casos, houve, por parte do entrevistado, pedido de 'permissão' para gravar o próprio depoimento, a fim de garantir que "não fosse deturpado e depois usado" contra ele. No entanto, se podíamos sentir este marco coletivo outros pontos começaram a se particularizar. Com o aumento do número de entrevistas e o entrecruzamento das informações, fomos encontrando outros sentidos aos silêncios dos 
entrevistados. Percebemos que, se a intervenção repressiva do regime militar gerara efeitos diretos em termos dos medos e temores dos entrevistados, daí haviam surgido efeitos paralelos. Como exemplos de alguns dos motivos por trás dos silêncios, enfrentados pela pesquisa, citaríamos quatro casos:

- Entrevistado (a): Na década de 50, militou nas fileiras do sindicato, ainda que em posição contrária aos comunistas. Em 1964, integrou a junta governativa de intervenção empossada pelos militares "contra os comunistas".

- Entrevistado (b): Militante sindical comunista de base. Ao ser preso, em 1964, diante das pressões, segundo outros depoimentos, delatou alguns companheiros com quem havia atuado.

- Entrevistado (c): Militante sindical comunista. Foi submetido a duros interrogatórios por ter desempenhado papel proeminente no sindicato. Ao longo do inquérito, viu seu nome envolvido em delações e denúncias fraudulentas. Dentre os entrevistados, foi um dos que mais mostrou resistências iniciais a "responder perguntas".

- Além destes três casos, um outro, ainda mais radical, foi aquele que envolveu um dos possíveis entrevistados selecionado por nós. Militante comunista no sindicato no final dos anos 50/início dos 60 , ele se negou terminantemente a dar entrevista. Soube-se, depois, que havia se convertido, tornando-se pastor evangélico, exorcizando seu passado.

Assim, por trás do silêncio coletivo, podiam-se encontrar também razões individualizadas que, agrupadas, se transformavam na justificativa do grupo. O não falar, de certa forma, era a face externa, mais eloqüente, do pacto consciente ou inconscientemente selado entre os agentes.

É importante perceber o porquê desta coletivização de silêncios. O Grêmio, de certa forma, harmonizava todas as diferenças do passado. Elas não eram esquecidas, não eram extintas, mas preteridas em nome de uma unidade contra um inimigo externo. Este inimigo poderia estar supostamente distante, como o governo com suas medidas punitivas aos aposentados; ou ainda, muito próximo, dividindo o mesmo prédio, como a direção do sindicato e seus dirigentes 'novatos', que, como diziam os 'velhos', "não se importavam com a história da categoria", "não consultavam os mais antigos", haviam, mesmo. "esquecido" deles.

A reação inicial do grupo com relação às entrevistas se devia ao fato de que ela faria retornar momentos que, de alguma maneira, o grupo gostaria de esquecer. Ainda que por motivos individuais, o coletivo parecia querer calar. Alguns sabiam que, no processo de entrevistas, apareceria claramente seu trabalho de "interventor da ditadura". Outros temiam que um dos entrevistados levantasse suspeitas sobre sua atitude nos interrogatórios e o apontasse como "delator". Enfim, a pesquisa acabou sendo vista como algo que poderia servir para trazer de volta um tempo a ser esquecido. 
Além disso, vale lembrar que, para muitos, a própria situação de fornecer informações já seria um incômodo, tendo em vista os interrogatórios e as pressões pelas quais passaram, e que não gostariam de lembrar. Por estes motivos é que, em um primeiro momento, o coletivo se insurgiu, coeso, contra algo que poderia quebrar a unidade do grupo. Falar sobre o passado, além de suas dores inerentes, serviria dificultar o bom andamento da vida do grupo no presente.

No entanto, a necessidade e o interesse de falar, sentidos por alguns dos seus membros, foi mais forte. Muitos viram nas entrevistas justamente a chance de tentar acertar contas com este passado. À época dos acontecimentos, a ditadura lhes havia impedido de falar, ou - o que talvez tenha sido ainda pior - lhes obrigado a falar o que não queriam. No presente, de alguma maneira, a consciência coletiva do grupo lhes impedia de se pronunciar devido às possíveis quebra de sigilo do passado e ruptura da unidade, no presente.

Nas entrevistas individuais, entretanto, livres dos olhares do grupo, os indivíduos tentavam trabalhar a memória individual - ainda que articuladamente à do coletivo $^{14}$-, lidando com as traumáticas situações pelas quais passaram sob a ditadura militar.

Esta mesma perspectiva individual foi o elemento primordial para que o grupo, ou a maior parte dele, modificasse sua posição frente às entrevistas. Ao perceberem que, aos poucos, indivíduos isoladamente iam aceitando participar da pesquisa, mesmo os mais resistentes começaram a sinalizar com o desejo de também dar entrevistas. Vale dizer que, em certos casos, alguns tentavam organizar entrevistas coletivas, quase sempre sob a alegação de "evitar deturpações". De forma sutil, fomos driblando esta proposta e consolidando as entrevistas individuais.

Com o desenrolar das entrevistas, era bastante freqüente os entrevistados demonstrarem vontade de saber o que uns haviam dito dos outros. Em muitas ocasiões, as entrevistas serviam para tentar passar uma nova versão de acontecimentos envolvendo os entrevistados, ou ainda, ao menos, fornecer uma certa justificativa para determinadas ações.

A situação-limite produzida pela ditadura gerou diversos resultados no interior do grupo atingido. De forma geral, o trauma produzido pelos interrogatórios, em muitos indivíduos, fazia com que buscassem, primeiro, evitar completamente as entrevistas; depois resistir a algumas perguntas que pudessem levá-los a trabalhar pontos com os quais não estavam dispostos a mexer. Não foram raros os momentos nos quais a emotividade tomou conta dos entrevistados quando os mesmos tentavam trabalhar algumas questões. ${ }^{15}$ Este impacto coletivo, porém, se desdobrou em variados efeitos individualizados. Eles serão fatores de sustentação e reforço do silenciamento coletivo, mas, ao mesmo tempo, também de enfraqueci42 mento. 
Decorrente desta perspectiva individual, um outro fator que auxiliou muito a pesquisa em termos da quebra do silêncio, foi a relação construída no âmbito familiar dos entrevistados. Tendo em vista que os impactos da repressão atingiram não só integrantes do grupo, como também seus amigos e familiares, estes se tornavam também peças importantes na montagem de nosso mosaico.

Em muitas entrevistas realizadas nas casas dos trabalhadores, familiares principalmente as esposas - interrompiam a entrevista passando pela sala, a todo instante, tecendo comentários rápidos sobre episódios e fatos que envolviam o entrevistado e foram traumáticos para a família. Com relação a isso, por terem um certo desprendimento perante aos outros envolvidos e seu presente comum no Grêmio, muitas vezes, os familiares teciam comentários bastante ácidos sobre a participação do entrevistado, o que era evitado por ele.

Esta participação familiar nas entrevistas serviu também para que aqueles que, de alguma maneira, foram vítimas da violência repressiva - do tipo: ser seguido na rua ostensivamente, receber 'visitas' policiais em casa, ficar sem notícias de familiar foragido etc. - sem estarem ligados diretamente aos acontecimentos, pudessem dar seu parecer sobre tudo, até mesmo expondo visões críticas sobre o entrevistado.

Nestas verdadeiras intervenções nas entrevistas, eram muito freqüentes as considerações sobre o abandono ao qual o entrevistado relegara a família por conta de suas atividades político-sindicais. Às críticas à situação financeira precária pela qual passara a família, agregavam-se aquelas relativas às ausências em momentos importantes como doença ou datas familiares (eventos alegres: aniversários, nascimentos, comemorações etc.; ou tristes: enterros, despedidas etc.). Este quadro deixava os entrevistados em situações embaraçosas, bastante constrangidos com as colocações que eram feitas.

Nossa percepção dos silêncios dos entrevistados ficou mais ampliada a partir da incorporação da perspectiva familiar. Pudemos compreender a extensão dos impactos causados pela ação repressiva sobre os momentos mais cotidianos dos perseguidos, e como isto, já bastante tempo depois, ainda gerava tanta emoção represada.

\section{UMA APROXIMAÇÃO RENOVADA}

O trabalho da memória realizado pelos entrevistados resultou em uma alteração de postura com relação à pesquisa. Se, de início, resistiram o quanto puderam, paulatinamente foram deixando de lado muitas das resistências. Interessante é que depois desta mudança, alguns dos entrevistados chegaram a assumir e revelar as suas resistências anteriores e as estratégias que utilizavam, conscientemente, para nos manter fora do tema que não lhes agradava. 
Este tipo de alteração teve ligação clara e direta com o processo de reaproximação de cada um com temas que lhe eram pouco, ou nada, confortáveis. Isto pôde ser sentido em muitos momentos nos quais, após ter evitado tocar em certo pontos, o entrevistado posteriormente desejar falar dos mesmos; ou, depois de resistir em conceder entrevista, ele mesmo procurar os pesquisadores. Não foi raro ouvirmos, no estágio mais avançado das entrevistas, afirmações do tipo "eu agora trabalho na pesquisa com vocês". ${ }^{16}$ Isto mantinha estreita relação com a capacidade do entrevistado de, neste novo momento, poder transitar por temas e períodos de sua vida que até então pareciam intransitáveis. Os entrevistados passaram, então, a revalorizar a própria história. ${ }^{17}$

A indicação, de alguns entrevistados, sobre estratégias que utilizavam para desviar-nos de assuntos dos quais não queriam tratar trouxe à pesquisa uma reflexão sobre os modos de agir dos demais. Com isto, pôde-se manter um novo tipo de relação ao longo das entrevistas, quando limites e resistências foram mais bem compreendidos e trabalhados.

Da relação estabelecida com os entrevistados, puderam-se retirar não só elementos que alargassem as possibilidades contidas nos documentos escrito obtidos no destroçado acervo sindical, mas, sobretudo, a abertura para a construção de fontes que contribuíram bastante para a ampliação do escopo da pesquisa. Uma parte da história e da memória operária pôde, assim, deixar de estar encoberta e silenciada.

As práticas repressivas da ditadura sobre o grupo produziram efeitos diretos e indiretos, os quais, correlativamente, produziram diferentes tipos de silêncios no interior do grupo. Termos percebido os níveis diferenciados de silêncios e sua articulação foi um ponto importante do trabalho. Isto promoveu a possibilidade de gerenciarmos estratégias mais individualizadas e uma maior aproximação ao entrevistado. A partir do silêncio geral do grupo - que, em um primeiro momento, pareceu, pois se apresentava, fruto de um mesmo ânimo -, buscamos as especificações que se conformavam no interior desta fachada. As entrevistas que visavam a outro tipo de questões acabaram por esbarrar com esta problemática, e precisou-se lidar com ela para alcançar o objetivo principal.

A aproximação renovada com os entrevistados possibilitou-me travar contato direto com a capacidade dos indivíduos em termos dos processos de construção e reconstrução da identidade individual e coletiva, e das múltiplas possibilidades contidas nas relações por eles desenvolvidas. Da desconfiança e rechaço inicial, paulatinamente, foi-se entrando no reino da confiança e cumplicidade. Isto rendeu frutos acadêmicos a partir dos resultados do trabalho, mas, também, atendendo à pluralidade do humano, longas tardes de cafés, bolos e saborosas conversas, que não 44 se encerraram ao término da pesquisa. 


\section{NOTAS}

1. Pesquisa coordenada pelo Prof. José Ricardo Ramalho (IFCS/UFRJ). As entrevistas que resultaram deste trabalho se encontram no Arquivo de Memória Operária do Rio de Janeiro (AMORJ/IFCS/UFRJ). A análise aqui realizada, de minha inteira responsabilidade, se baseia na experiência em entrevistas realizadas individualmente pelo autor ou em conjunto com outros membros da pesquisa (em alguns casos, José Ricardo Ramalho e, em outros, Lisa Stuart).

2. Ver, entre outros, os trabalhos de Francisco Weffort (1973 e 1978).

3. Por exemplo, Erickson (1979) e Telles (1962).

4. O exemplo maior é o de Benedito Cerqueira. Presidente do sindicato por sucessivas gestões no período 1955-1964, Cerqueira ocupou cargos também na Comissão Permanente de Organizações Sindicais, a CPOS, e no Comando Geral dos Trabalhadores, o CGT. Embora trabalhista, Cerqueira retirava grande parte de sua sustentação da militância comunista.

5. Ver mais informações a respeito em Santana (1992).

6. Além da quase total destruição promovida pela ação do governo militar, o acervo sindical estava bastante desfalcado pela própria retirada de material por parte dos militantes à época da ação policial. Agravando ainda mais o quadro, era evidente o desleixo das novas gerações de militantes em relação à documentação.

7. Em uma versão bastante áspera daquilo que Gomes $(1988$, p. 13) chamou de "atitude clássica do depoente (ou seus familiares), que antes de ser entrevistado, procura entrevistar o entrevistador".

8. Este tipo de problema na experiência com militantes operários, em suas diferentes matizes, já foi indicado por outros pesquisadores. Gomes (1988, p. 13), por exemplo, no processo de entrevistas com velhos militantes, experimentara o medo e a desconfiança de seus entrevistados, "que tiveram participação política em anos tão recuados no tempo", mas que ainda temiam "represálias para si e para os seus". Mesmo que suas entrevistas tenham se dado ainda sob o governo militar do general João Figueiredo, o que de certa maneira poderia justificar a atitude de seus entrevistados, o autor [Gomes] (1988) avançava uma possibilidade de reflexão mais geral a partir da idéia de que "é preciso recordar que estamos no Brasil, país que tem enorme dificuldade em exorcizar fantasmas como o do comunismo e o da subversão, e onde os trabalhadores militantes têm presentes na memória a facilidade e a brutalidade com que a repressão deles sempre se encarregou". Em nosso caso, como veremos, por se tratar de um grupo estruturado, e não de depoentes isolados, a complexidade em termos dos medos e desconfianças era maior.

9. Inicialmente, pensávamos em entrevistar aqueles que, em cargos de direção ou não, constavam de atas e documentos sindicais compulsados pela pesquisa. Depois, porém, dada a dificuldade enfrentada e a crescente importância dos testemunhos orais, flexibilizou-se este universo. 
10. Este tipo de preocupação e prática contrastam com a postura de comunistas já mais identificados publicamente que, em grande medida, não apresentavam tanto problema com entrevistas, conforme pode ser verificado em Pandolfi (1995).

11. A temática da ação dos militantes sindicais comunistas foi foco de minha análise tanto na dissertação de mestrado, como na tese de doutorado.

12. Para uma análise da relação história oral/história de vida, ver, entre outros: Debert (1986), para quem a história oral e história de vida podem ser pensadas como distintas; embora muitas vezes, por serem utilizadas conjuntamente, se confundam; e Queiroz (1988), que indica ser a história de vida uma espécie, ao lado de outras, no interior do amplo ramo da história oral.

13. Michael Pollak (1993), em seu estudo com ex-prisioneiros de campos de concentração, indica postura semelhante por parte de seus entrevistados, indicando toda a dor e emotividade represadas envolvidas no processo. Os trabalhos de Pollak foram de grande importância para a tematização e compreensão da questão do silêncio em nossa pesquisa.

14. Halbwachs (1990) chama a atenção para a articulação entre a memória individual e a memória coletiva e as formas pelas quais esta informa e fornece marcos para aquela. Para uma análise mais detalhada dos marcos coletivos da memória dos militantes metalúrgicos do pré-64 e uma comparação destes com os da memória dos chamados "novos militantes", ver Santana \& Nascimento (1994).

15. Este processo de construção e reconstrução do eu do indivíduo tendo como um dos suportes o processo de entrevista foi indicado por Thompson (1992).

16. A contribuição dos entrevistados ia mesmo além da entrevistas. Muito material iconográfico e escrito foi conseguido por intermédio deles, o que forneceu ainda mais subsídios para a pesquisa histórica.

17. Antes um local a ser evitado, entre outras coisas, símbolo de derrota política e perseguição, o passado tornou-se fonte de orgulho para alguns entrevistados. Em certos momentos, serviu até mesmo para uma reaproximação renovada entre eles e os familiares. Como exemplo, indicaríamos o caso de um entrevistado que remetia a sua filha distante todos os recortes de jornais em que se divulgavam os vários eventos realizados pela pesquisa, nos quais os entrevistados apareciam como protagonistas. Além do orgulho por ver seu nome estampado nos jornais em posição de destaque, talvez fosse a maneira encontrada por ele para justificar todas as ausências a que submetera a família no passado. Se com a derrota e a perseguição as ausências não conseguiriam ser explicadas, com este novo contato com o passado, podia-se justificá-las. Elas haviam sido por uma boa causa, que agora, depois de tanto tempo, havia sido valorizada.

\section{REFERÊNCIAS BIBLIOGRÁFICAS}

DEBERT, G. Problemas relativos ao uso da história de vida e da história oral. In: CARDOSO, R. (Org.) A Aventura Antropológica. Rio de Janeiro: Paz e Terra, 1986. 
ERICKSON, K. P. Sindicalismo no Processo Político no Brasil. São Paulo: Brasiliense, 1979.

FERREIRA, M. de M. \& AMADO, J. (Orgs.). Usos \& Abusos da História Oral. Rio de Janeiro: Editora da Fundação Getúlio Vargas, 1996.

GOMES, A. de C. (Coord.). Velhos Militantes. Rio de Janeiro: Zahar, 1988.

HALBWACHS, M. A memória coletiva. São Paulo: Vértice, 1990.

LE GOFF, J. História e Memória. Campinas: Unicamp, 1992.

ORLANDI, E. P. As Formas do Silêncio. Campinas: Unicamp, 1992.

PANDOLFI, D. Camaradas e companheiros - história e memória do PCB. Rio de Janeiro: RelumeDumará, 1995.

POLLAK, M. La gestion de l'indicible. Actes de la Recherche, 1986, n. 62/63, p. 30-53. L'Expérience Concentrationnaire. Paris: Métaillé, 1993.

QUEIROZ, M. I. P. de. Relatos orais: do “indizível” ao “dizível”. In: SIMSON, Olga de Moraes von (Org.). Experimentos com Histórias de Vida (Itália - Brasil). São Paulo: Vértice, 1988.

SANTANA, M. A. Partido e militância sindical: a atuação comunista no Sindicato dos Metalúrgicos do Rio de Janeiro (1947/1964), 1992. Dissertação de Mestrado. Rio de Janeiro, UFRJ.

The past and the present in the accounts of two generations of militant workers. Communicating Experience. v.3, IX International Oral History Conference, International Oral History Association, Gotemburgo, 1996.

. Esquerda e Sindicato no Brasil: o PCB (1945/1992), 1998. Tese de Doutorado. Rio de Janeiro, UFRJ.

SANTANA, M. A e NASCIMENTO, R. M. "Trabalhadores do Brasil" e "Peões": passado e presente na fala de duas gerações de militantes operários. Trabalho apresentado na XVIII Reunião Anual da ANPOCS, GT História Oral e Memória, Caxambu, 1994.

SIMSON, O. de M. von. (Org.). Experimentos com Histórias de Vida (Itália - Brasil). São Paulo: Vértice, 1988.

TELLES, J. O Movimento Sindical no Brasil. Rio de Janeiro: Vitória, 1962.

THOMPSON, P. A Voz do Passado - bistória oral. Rio de Janeiro: Paz e Terra, 1992.

WEFFORT, F. Origens do sindicalismo populista no Brasil (A conjuntura do após-guerra). Estudos Cebrap, São Paulo, n. 4, abr./jun, 1973.

- Democracia e movimento operário: algumas questões para a história do período 1945/1964. Revista de Cultura Contemporânea, São Paulo, n. 1, 1978. 